\section{Laparoscopic versus open repair of inguinal hernia}

\section{Paper should have put more emphasis on benefits of laparoscopic repair}

EDrroR,-Kate Lawrence and colleagues report excellent early results of their trial comparing laparoscopic with open hernia repair and show that patients prefer laparoscopic repair. ${ }^{1}$ With only 125 subjects, they found significant benefits in terms of pain scores and quality of life assessments in the early postoperative period after laparoscopic repair. They rightly conclude, however, that the single important criterion for success in hernia repair is the recurrence rate and that a far larger sample will have to be followed up for far longer for this be determined.

It is a pity that the paper and the paragraph on the "This week in $B M$ \%" page place greater emphasis on the increase in minor complications with this form of surgery than on the benefits, even though only one of the seven complications in the patients who had laparoscopic repair (early recurrence of a direct hernia) is clinically important. After all, the patients preferred the laparoscopic operation despite their haematomas and seromas. Furthermore, we are not told whether the patient with early recurrence differed from the others in any way, or the level of the operator's experience; this is important information even though the operator's experience did not affect the overall rate of complications. Incidentally, the authors seem to have "lost" one complication: they write that there were two, three, and one complication for the teams with the lowest, intermediate, and highest experience respectively, whereas they also say that there were seven complications in total.

Costs are notoriously difficult to quantify. A

\section{Advice to authors}

We receive more letters than we can publish: we can currently accept only about one third. We prefer short letters that relate to articles published within the past four weeks. Letters received after this deadline stand less chance of acceptance. We also publish some "out of the blue" letters, which usually relate to matters of public policy.

When deciding which letters to publish we favour originality, assertions supported by data or by citation, and a clear prose style. Wit, passion, and personal experience also have their place.

Letters should have fewer than 400 words and no more than five references (including one to the $B M F$ article to which they relate); references should be in the Vancouver style. We welcome pictures.

Letters should be typed and signed by each author, and each author's current appointment and address should be stated. We encourage you to declare any conflict of interest.

Please enclose a stamped addressed envelope if you would like to know whether your letter has been accepted or rejected.

Letters will be edited and may be shortened. major difference between the two groups is the cost of an extra surgical registrar, but whether he or she is any more required for laparoscopic than for open surgery is debatable. Also, operating time depends on the operator's experience and will fall as more patients are operated on. There are other ways of reducing costs. This trial was started a few years ago, when the transabdominal preperitoneal approach was the standard operation. The extraperitoneal approach is quicker, does not require expensive disposable stapling equipment, and has the added advantages of greater safety and permitting the use of local anaesthesia. ${ }^{2}$ Furthermore, there is so little postoperative discomfort that the procedure can easily be done on a day case basis.

The debate concerning the modern management of inguinal hernia continues, and we urgently require more trials such as this and the Medical Research Council's current trial in Aberdeen ${ }^{3}$ to provide the answers.

136 Harley Street,
London WIN $1 \mathrm{AH}$

M H ORNSTEIN General surgeon

1 Lawrence $\mathrm{K}$, McWhinnie D, Goodwin A, Doll H, Gordon A, Gray A, et al. Randomised controlled trial of laparoscopic versus open repair of inguinal hernia: early results. $B M \mathcal{F}$ 1995;311:981-5. (14 October.)

2 Ornstein MH. Prospective trial comparing Lichtenstein with laparoscopic tension-free mesh repair of inguinal hernia. $\mathrm{Br} \mathcal{F}$ Surg 1995;82:1700.

3 Baxter JN, O'Dwyer P, Macintre I, Grant A, Kennedy A, Donaldson C, et al. Put hernia option to controlled test. Hospital Doctor 1995 Sep 14:14.

\section{Long term recurrence may be lower with laparoscopic repair}

EDITOR,-In their study comparing laparoscopic with open repair of inguinal hernias Kate Lawrence and colleagues excluded $43 \%$ of patients considered for the trial.' This is a high proportion: in our study five patients $(3 \%)$ seen during the trial fulfilled our exclusion criteria. ${ }^{2}$

More complications occurred in the group that had laparoscopy in the authors' study. The surgical technique used probably accounts for three of the complications reported. The $12 \times 8 \mathrm{~cm}$ mesh is too small and will result in recurrences; a $15 \times 10 \mathrm{~cm}$ mesh is now widely accepted for unilateral repairs. In addition, the surgeons interposed mesh between the inferior epigastric vessels and the abdominal wall, which is unnecessary for fixation and presumably led to another complication-namely, vessel injury.

Cord seromas or haematomas occur quite often but have no sequelae and do not inhibit return to work. As the authors postulate, the problem may be prevented by transection of the sac rather than full dissection of the sac from the cord. Modification of the surgical technique would therefore have avoided three complications, and the remaining four complications may not be clinically important.

The mean time for the laparoscopic operation (72 minutes) is slow compared with that taken by most surgeons who are experienced in laparoscopy. The last 20 procedures in our trial took a mean of 30 minutes, with reduced cost implications. Costs also included the cost of an assistant to hold the camera. This is increasingly being done by the scrub nurse. Clearly trainee surgeons assist to be trained, but their presence is not essential.
Recently we have repaired some irreducible hernias laparoscopically. A combination of external pressure and internal manipulation and dissection has enabled peroperative reduction and laparoscopic repair.

Finally, on questioning, the authors found that the patients were most worried about recurrence. Long term studies are not available, although indications are that recurrence rates will be $1 \%$ or less and that most recurrences will occur within a few months of the repair. Recurrence rates as high as those for open darned repair therefore seem unlikely. Roughly half of recurrences after conventional open repair occur within two years.

The comparison that needs to be made is between a laparoscopically placed mesh and an open mesh repair under local anaesthesia. A randomised prospective trial is under way at Whipps Cross and the North Middlesex Hospitals.

JAMES WELLWOOD

Consultant surgeon

Whipps Cross Hospital,

DAVID STOKER Consultant surgeon

North Middlesex Hospital,

London N18 1QX

1 Lawrence K, McWhinnie D, Goodwin A, Doll H, Gordon A, Gray $A$, et al. Randomised controlled trial of laparoscopic versus open repair of inguinal hernia: early results. $B M F$ 1995;311:981-5. (14 October.)

2 Stoker DL, Spiegelhalter DJ, Singh R, Wellwood J. Laparoscopic versus open inguinal hernia repair: randomised prospective trial. Lancet 1994;343:1243-5.

\section{Surgeons in study were inexperienced at laparoscopic repair}

EDrToR,-Kate Lawrence and colleagues conclude that more complications occur after laparoscopic than after open repair of inguinal hernias and that costs are higher.' There are, however, several flaws in their study.

At the start of the study the most experienced laparoscopic surgeon had performed only 20 repairs and the others had performed fewer, though the number is not stated. It is questionable whether comparing the laparoscopic repairs of surgeons on the steep part of the learning curve (which would include the surgeon who had done 20 repairs) with their experience of open hernia repair, which no doubt amounted to many hundreds of cases, is a fair evaluation of the technique.

The authors' theatre staffing perhaps reflects the approach of affluent teaching hospitals to both medical and nursing staff, with both a senior theatre nurse and a surgical registrar being present in addition to the operating surgeon. In Colchester, and no doubt many other district general hospitals, laparoscopic hernia repair is performed without any assistant other than the scrub nurse, who is usually in $\mathrm{E}$ or $\mathrm{F}$ grade.

In two cases the procedure was converted to open repair because of incarcerated hernias. This reflects the relatively small individual experience of each surgeon: in my experience of more than 400 laparoscopic hernia repairs, conversion to open surgery has never been necessary and all incarcerated hernias have been reduced laparoscopically.

With equivalent operative experience (that is, hundreds of repairs), operating time for laparoscopic repair is similar to, or only marginally longer than, that for open repair of a unilateral 